\title{
Synthesis of some novel 4-thiazolidinone compounds and their application as potential antimicrobial agent
}

\author{
J. A. Patel, B. D. Mistry* and K. R. Desai \\ Department of Chemistry, B. K. M. Science College, Valsad-396 001, Gujarat, India
}

Manuscript received 14 July 2005, revised 4 January 2006, accepted 28 June 2006

\begin{abstract}
Chloro-l-[5'-hydroxy-2'-(phenyldiazenyl)phenyl]-4-[2"-hydroxy-5'"-(1"', $3^{\prime \prime \prime}-$-benzothiazol-2"'-yl-diazenyl)phenyl]-

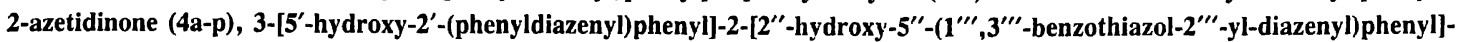
4-thiazolidinone (5a-p) and 3-[5'-hydroxy-2'-(phenyldiazenyl)phenyl]-2-[2"'-hydroxy-5' $-\left(1^{\prime \prime \prime}, 3^{\prime \prime \prime}\right.$-benzothiazol-2'"'-yldiazenyl)phenyl]-4-methylthiazolidinone have been synthesized from their Schiff bases (3a-p). They have been screened for their antimicrobial activities.
\end{abstract}

Keywords : 4-Thiazolidinone, antimicrobial agent.

Various 2-azetidinones ${ }^{1}$ and 4-thiazolidinones ${ }^{2,3}$ are endowed with wide range of pharmacological ${ }^{4,5}$ activities, such as CNS, CVS, antibacterial, analgesic, antifungal etc. 2,3-Diaryl-1,3-thiazolidin-4-ones have been proved to be highly effective in inhibiting HIV $-1^{6}$ and $\mathrm{TB}^{7}$ mycobecterias. While 2-azetidinone derivatives have been reported to possess anti-inflammatory-anticonvulsant and antifungal ${ }^{8}$ activities.

5-(1', 3'-Benzothiazol-2-yl-diazenyl)-2-hydroxybenzaldehyde under reflux with 3-amino-4-(phenyldiazenyl)phenol, gives Schiff bases (3a-p). 3-Chloro-1[5'-hydroxy-2'-(phenyldiazenyl)phenyl]-4-[2"-hydroxy$5^{\prime \prime}-\left(1^{\prime \prime \prime}, 3^{\prime \prime \prime}\right.$-benzothiazol-2"' -yl-diazenyl)phenyl]-2azetidinone (4a-p) was obtained by cycloaddition of chloro acetylchloride and triethylamine to Schiff base. The cycloaddition of thioglycolic acid and thiolactic acid to Schiff base gives the corresponding 4-thiazolidinones (5a-p) and (6a-p) according to the Scheme 1.

\section{Results and discussion}

Antimicrobial activity: The compounds were screened for antibacterial activity against $E$. coli, $S$. aureus, Pseudomonas, Bacillus and antifungal activity against Candida by disk diffusion method at a concentration of $100 \mu \mathrm{g} / \mathrm{ml}$.

The stock solution of the compounds was prepared at a concentration of $5 \mathrm{mg} / \mathrm{ml}$ and from stock solution the disc was prepared at a concentration of $100 \mu \mathrm{g} / \mathrm{ml}$. The testing was done on muller hinton agar plates, by swabbing the agar plates with respective cultures, and placing the disc on it and incubating at $37^{\circ} \mathrm{C}$ for $24 \mathrm{~h}$. In series 3a-p, compounds $\mathbf{3 b}, \mathbf{3 e}, \mathbf{3 f}, \mathbf{3 k}, \mathbf{3 m}$ and $\mathbf{3 o}$ shows mild activity (zone of inhibition $4-8 \mathrm{~mm}$ ) against $E$. coli, whereas $\mathbf{3 g}, \mathbf{3 h}, \mathbf{3 i}$ and $\mathbf{3 j}$ show moderate (zone of inhibition $9-12 \mathrm{~mm}$ ) activity against $E$. coli. Compound $\mathbf{3 f}$, $3 \mathrm{~g}, 3 \mathbf{j}$ show mild (zone of inhibition 4-8 $\mathrm{mm}$ ) activity against Pseudomonas, while $\mathbf{3 e}, \mathbf{3 h}$ and $\mathbf{3 i}$ shows moderate activity against Pseudomonas. In series 3a-p, almost all compounds are inactive against $S$. aureus and Bacillus, whereas these compounds show good activity against Candida. In the series of compounds (4a-p), 4e, 4f, $4 \mathrm{~h}$ and $4 \mathbf{i}$ show moderate activity against $E$. coli, whereas $4 a, 4 c, 4 d, 4 k$ and $4 m$ show mild activity against the same. 4e, 4f, $4 \mathrm{~h}$ and $4 \mathrm{i}$ show moderate activity against Pseudomonas, whereas in series 4a-p almost all compounds are inactive against $S$. aureus and Bacillus. In the series of compounds (5a-p), $5 \mathbf{h}, 5 \mathbf{i}$ and $5 \mathbf{j}$ show moderate activity against $E$. coli whereas these compounds are found to be mild active against $S$. aureus and Bacillus. 5c, $\mathbf{5 f}$, $\mathbf{5 g}, \mathbf{5 h}, \mathbf{5 j}$ and $\mathbf{5 k}$ show good activity against Candida. In a series of compounds (6a-p), $\mathbf{6 f}, \mathbf{6} \mathbf{i}$ and $\mathbf{6 j}$ show moderate activity against Candida while they show mild activity against E. coli and Pseudomonas. Tetracycline, Ceftriazone and Greseofulvin were taken for comparison purpose.

The results are given below :

$$
\text { Zone of inhibition of standard drug in } \mathrm{mm}
$$

\begin{tabular}{lcccccc} 
E. coli & Pseudomonas & S. aureus & Bacillus & & Candida \\
Tetracycline & 16 & 14 & 15 & 17 & - \\
Ceftriazone & 30 & 28 & 30 & 28 & - \\
Greseofulvin & - & - & - & - & $15-20$ \\
\hline
\end{tabular}




\section{Experimental}

All m.ps. were taken in open capillaries using Toshniwal apparatus and are uncorrected. IR spectra $(\mathrm{KBr})$ were recorded on Shimadzu FT-IR 8300 spectrophotometer, ${ }^{1} \mathrm{H}$ NMR spectra on a Varian Geminy $200 \mathrm{MHz}$ spectrometer using TMS as the internal standard. Purity of the compounds in addition to elemental analysis was checked by TLC.

4-(1',3'-Benzothiazol-2'-yl-diazenyl)-2-\{[5"-hydroxy$2 "$-(phenyldiazenyl)phenyl]imino\}methylphenol (3a-p) : 5(1',3'-Benzothiazol-2'-yldiazenyl)-2-hydroxybenzaldehyde $(0.01 \mathrm{~mol}, 2.83 \mathrm{~g})$ is mixed with 3-amino-4-(phenyldiazenyl)phenol $(0.01 \mathrm{~mol}, 2.13 \mathrm{~g})$ and then refluxed in ethanol at $90{ }^{\circ} \mathrm{C}$ for $5-6 \mathrm{~h}$. After the reaction is over the solvent was removed by vacuum distillation. The solid product was filtered, dried and recrystallised from absolute alcohol. Other substituted Schiff bases were prepared in the same way : m.p. $85{ }^{\circ} \mathrm{C}$ : IR (KBr) $3460-3455$ $(-\mathrm{OH}), 1605-1600(\mathrm{C}=\mathrm{N}) .850-800 \mathrm{~cm}^{-1}$ (tri-substituted benzene); $\delta\left(\mathrm{CDCl}_{3}\right) 3 \mathrm{e}: 5.635(1 \mathrm{H}, \mathrm{s}, \mathrm{N}=\mathrm{CH}-\mathrm{Ar}), 6.90$ $7.96(14 \mathrm{H}, \mathrm{m}, \mathrm{Ar}-\mathrm{H}), 9.20$ (2H, s. Ar-OH).

3-Chloro-1-[ 5'-hydroxy-2'-(phenyldiazenyl)phenyl]-4[2"-hydroxy-5"-(1"', $3^{\prime \prime \prime}$-benzothiazol-2"'-yldiazenyl)phenyl]-2-azetidinone (4a) :

A solution of $3 \mathrm{a}(0.01 \mathrm{~mol}, 4.78 \mathrm{~g})$ in benzene was added to a well stirred mixture of chloroacetyl chloride $(0.012 \mathrm{~mol})$ and triethylamine $(0.012 \mathrm{~mol})$ in benzene. The reaction mixture was refluxed for $15-16 \mathrm{~h}$. The product was isolated and recrystallized from ethanol : m.p. $140^{\circ} \mathrm{C}$; IR (KBr) $3630(-\mathrm{OH}), 1754-1738(\mathrm{C}=0), 1650$ ( $\mathrm{C}=\mathrm{N}$, thiazole), 776 (C-S, thiazole), 894-873 (tri-substituted benzene), $800-600 \mathrm{~cm}^{-1}(\mathrm{C}-\mathrm{Cl}) ; \delta\left(\mathrm{CDCl}_{3}\right) 4 \mathrm{~d}$ :

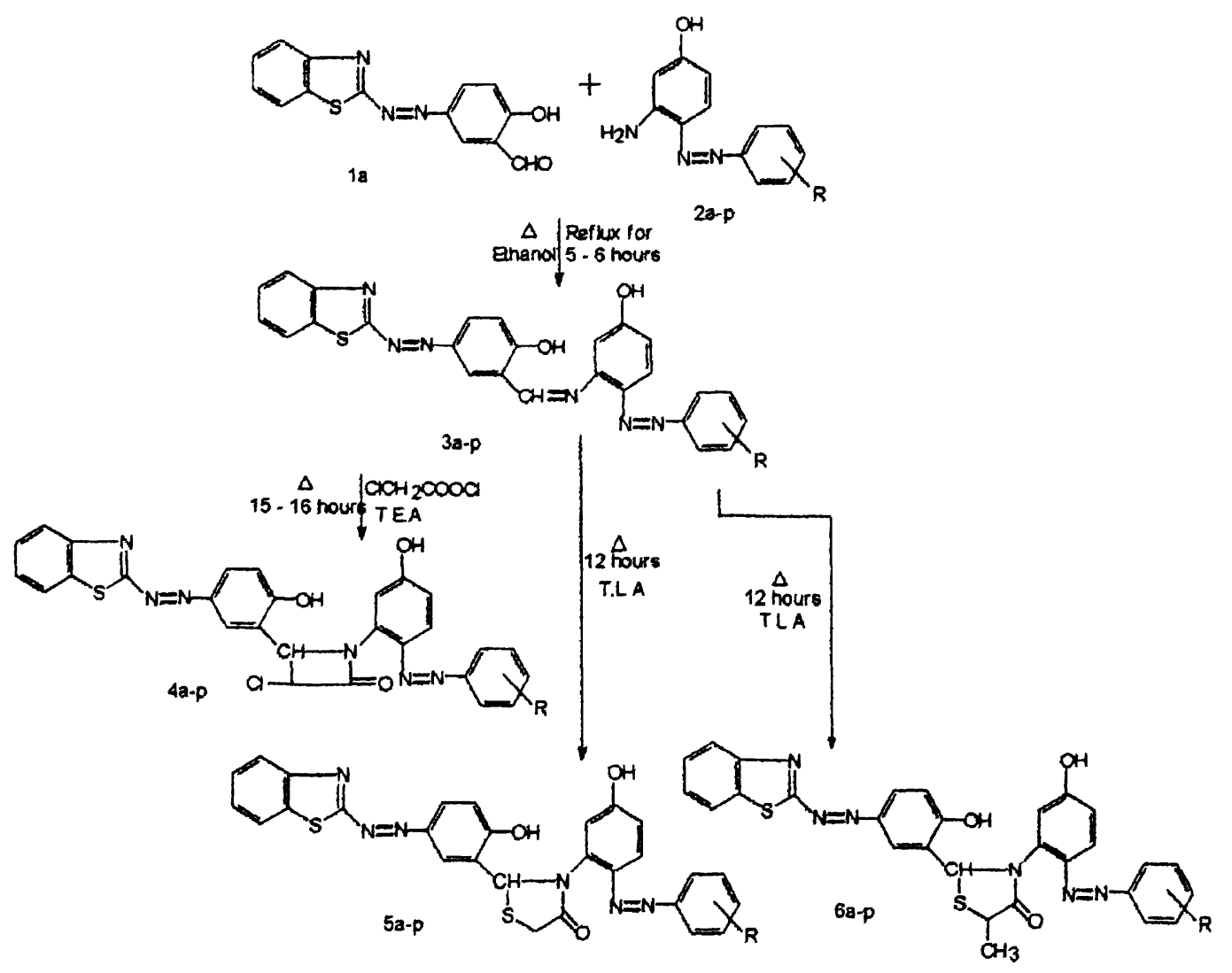

where $\mathrm{R}=\mathbf{a} ; \mathrm{H}, \mathbf{b} ; 2-\mathrm{OCH}_{3}, \mathbf{c} ; 3-\mathrm{OCH}_{3}, \mathbf{d}, 4-\mathrm{OCH}_{3}, \mathrm{e} ; 2-\mathrm{Br}, \mathbf{f} ; 3-\mathrm{Br}, \mathbf{g} ; 4-\mathrm{Br}, \mathrm{h} ; 2-\mathrm{Cl}, \mathbf{i} ; 3-\mathrm{Cl}, \mathbf{j} ; 4-\mathrm{Cl}, \mathrm{k} .2-\mathrm{NO}$, I, 3- $\mathrm{NO}_{2}, \mathbf{m}: 4-\mathrm{NO}_{2}, \mathbf{n} ; 2-\mathrm{CH}_{3}, \mathbf{0}: 3-\mathrm{CH}_{3}, \mathbf{p} ; 4-\mathrm{CH}_{3}$

Scheme 1. Synthesis of 4-thiazolidinone compounds (3a-p), (4a-p), (5a-p) and (6a-p). 
6.97-7.77 (14H, m, Ar-H), $8.2(1 \mathrm{H}, \mathrm{s}$, Ar-OH), 3.85 $\left(3 \mathrm{H}, \mathrm{d}, \mathrm{OCH}_{3}\right), 7.38(1 \mathrm{H}, \mathrm{s},-\mathrm{N}-\mathrm{CH})$.

3-[5'-Hydroxy-2'-(phenyldiazenyl)phenyl]-2-[2"-hydroxy-5"-(1"',3"'-benzothiazol-2"'-yl-diazenyl)phenyl]-4thiazolidinone (5a) :

The Schiff bases $(0.01 \mathrm{~mol}, 5.0 \mathrm{~g})$ in benzene were mixed with thioglycolic acid $(0.01 \mathrm{~mol}, 0.7 \mathrm{ml})$ in benzene and were refluxed for $15-16 \mathrm{~h}$. The reaction mixture was cooled and treated with $10 \% \mathrm{NaHCO}_{3}$ solution. The product was isolated and crystallized from ethanol : m.p. $289^{\circ} \mathrm{C}$; IR (KBr) $3540(-\mathrm{OH}), 1735(\mathrm{C}=\mathrm{O}$, thiazolidinone), 752 (C-S-C), 890-882 (tri-substituted benzene); $\delta\left(\mathrm{CDCl}_{3}\right) \mathbf{5 b}:$ 6.9-7.94 $(14 \mathrm{H}, \mathrm{m}, \mathrm{Ar}-\mathrm{H}), 7.99$ $(2 \mathrm{H}, \mathrm{s}, \mathrm{Ar}-\mathrm{OH}), 3.902\left(3 \mathrm{H}, \mathrm{d}, \mathrm{OCH}_{3}\right), 8.2(1 \mathrm{H}, \mathrm{s},-\mathrm{N}-$ $\mathrm{CH})$.

3-[5'-Hydroxy-2'-(phenyldiazenyl)phenyl]-2-[2"-hydroxy-5"-(1"',3"-benzothiazol-2"'-yl-diazenyl)phenyl]-4methylthiazolidinone (6a) :

A mixture of Schiff base $(0.01 \mathrm{~mol}, 5.0 \mathrm{~g})$ and thiolactic acid $(0.01 \mathrm{~mol})$ was heated at $120-125^{\circ} \mathrm{C}$ for $12 \mathrm{~h}$. The reaction mixture was cooled and treated with $10 \%$ $\mathrm{NaHCO}_{3}$ solution. The product was isolated and crystallized from ethanol : m.p. $73{ }^{\circ} \mathrm{C}$; IR $(\mathrm{KBr}) 3500$ (-OH), 1755-1750 ( $\mathrm{C}=\mathrm{O}$, thiazolidinone), 894-873 (trisubstituted benzene), $700-650 \mathrm{~cm}^{-1}(\mathrm{C}-\mathrm{S}-\mathrm{C}) ; \delta\left(\mathrm{CDCl}_{3}\right)$ 6a : $2.6\left(3 \mathrm{H}, \mathrm{s}, \mathrm{CH}-\mathrm{CH}_{3}\right), 8.3\left(1 \mathrm{H}, \mathrm{q}, \mathrm{CH}-\mathrm{CH}_{3}\right), 7.95-$
$8.5(1 \mathrm{H}, \mathrm{s}, \mathrm{N}-\mathrm{CH}), 6.9-7.5(14 \mathrm{H}, \mathrm{m}, \mathrm{Ar}-\mathrm{H}), 6.38(2 \mathrm{H}$, $\mathrm{s}, \mathrm{Ar}-\mathrm{OH})$.

\section{Acknowledgement}

We are grateful to the Department of Chemistry, B. K. M. Science College, Valsad (Veer Narmad South Gujarat University, Surat) for providing the necessary facilities for the research work.

\section{References}

1. K. Mogilaih, R. Babu Rao and K. Narender Reddy, Indian J. Chem., Sect. B, 1999. 38, 818.

2. K. D. Patel, B. D. Mistry and K. R. Desai. J. Indian Chem. Soc., 2004, 81, 783.

3. K. M. Mistry and K. R. Desai, E. J. Chem., 2004, 1, 189.

4. V. K. Pandey, V. D. Gupta, Mrinalini Upadhyay, Mridula Upadhyay, V. K. Shigh and M. Tandon, Indian J. Chem., Sect. B, 2005, 44, 158.

5. J. M. Parmar, J. J. Modha and D. R. Parikhs, Indian J. Chem., Sect. B, 1999, 38, 440.

6. J. J. Bhatt. B. R. Shah, H. P. Shah, P. B. Trivedi, N. K. Undavia and N. C. Desai, Indian J. Chem.. Sect. B, 1994. 33, 189.

7. P. S. Desai and K. R. Desai, J. Indian Chem. Soc., 1994, 71, 155.

8. S. K. Srivastava, S. Srivastava and S. D. Srivastava, Indian J. Chem., Sect. B, 1999, 38, 183. 